\title{
The emergence of theoretical physics in Argentina, Mathematics, mathematical physics and theoretical physics, 1900-1950
}

\author{
Eduardo L. Ortiz \\ Imperial College \\ London SW7 2AZ, United Kingdom \\ E-mail:e.ortiz@imperial.ac.uk
}

The emergence of studies on theoretical physics in Argentina prior to 1950, the year Héctor Rubinstein joined Buenos Aires University, is the topic of this paper. I first consider the impact in Argentina of philosophical ideas favorable to the promotion of experimental science, which emerged in the last two decades de the 19th century and reached physics towards 1900 . Then, I make reference to the influence of changes in these philosophical perceptions in the late 1910 and early 1920s, which gave more emphasis to theoretical studies and, again, of their impact on physics. Finally, the emergence of research in theoretical physics around 1935-45 and its relation to previous advances in mathematics research is briefly considered.

I also make reference to the impact of two scientific visitors to Argentina: first to Albert Einstein, who visited in 1925 and, fifteen years later, to George D. Birkhoff. The latter opened a wider channel of communication with the USA, which was developed further in the next decades.

This paper ends with a brief reference to changes in the physics scene of Argentina in the early $1950 \mathrm{~s}$ as a consequence of new institutional developments, and to the return of the universities to be the main seat of theoretical physics research, which began to happen in the second part of the 1950s. 
Quarks, Strings and the Cosmos - Héctor Rubinstein Memorial Symposium, AlbaNova, Stockholm, Sweden

August 9-11, 2010 


\section{Introduction}

There were several attempts to develop physics in Argentina through the19th century. The first of them, between 1817 and around 1830, when mathematician José de Lanz and physicist Ottavio Fabrizio Mossotti moved to Buenos Aires from Paris and London respectivey. After a complex period, in which the universities suffered neglect, there was a new effort in the 185060 s, particularly after the return of Santiago Cáceres, who had graduated in mathematics and physics at the University of Göttingen. Again in the 1880s, when Valentín Balbín, a gifted student sent to Europe for further training, returned to Buenos Aires. He lectured on modern analysis and algebra as well as on quaternions' theory, a topic on which he wrote a book which received positive reviews in Europe. In addition, together with Jorge Duclout, a graduate form the ETH, Zürich, Balbín created a Mathematics and Mathematical Physics Seminar at the Sociedad Científica Argentina in the early 1890s where topics such as space-time, nonEuclidean geometries and recent works on theoretical physics were discussed and papers published.

However, it was in the early 1900s when a considerable expansion took place as a Physics Institute was created at the new University of La Plata. In it physics acquired, for the first time in Argentina, a professional status. Following a long tradition in higher education in Argentina, which goes again back at least to Cáceres' times in the 1850s, German and German-trained teachers were invited to help rising the standard of the exact and natural sciences.

This paper briefly discusses the transition from mathematics and mathematical physics to the new subject of theoretical physics, as we know it today, in the Argentina of the first half of the 20th century. The first original research note on this subject appeared in 1926. In particular, I try to show that in addition to important requirements in fields of technology, particularly in connection with the development electricity and its applications, there was an important- and often neglected- cultural component which, in the Argentina of the late 19th century, is associated with the predominance of trends related to French Positivism. The transition from Positivism to new and more sophisticated formulations, carrying a more critical analysis of the concept of experiment and giving more weight to theoretical studies had, I argue, a considerable impact on the directions of the official support given to science and on the early path of theoretical physics in Argentina, particularly in the 1920s.

\section{The Positivist experiments: La Plata}

Although Argentina lived through a deep financial crisis in 1890, by the turn of the century, through massive exports of leather, wool, corn, and later of beef, restored its financial position and by 1910 it was again a prosperous country. This circumstance made a radical modernization of its infrastructure possible and, as we shall see, some of the initiatives of this period affected the development of physics in Argentina.

Tensions arising from the expansion of commerce and the demands of modern technology provided a context for the development of physics in Argentina, which is discussed in some detail in [1], [2]. However, they were not the only factor. There was also, in different periods, a significant cultural component which affected the contemporary perception of 
science and gave its promotion a definite signature. The impact of this component on official science policy decisions can be detected in several periods of Argentina's history, when key pedagogical choices had to be made. For example, in the perception of technology as an epilogue to a pure-science training when the university engineering school was designed in the late 1860 s, a decision which affected the development of physics.

By the end of the century philosophical thought in Argentina was dominated by an amalgam of ideas for which French Positivism offers a useful label. However, it also contained elements of Scientism and Pragmatism. By 1900 these new views had already impacted the humanities. New and valuable studies began to appear on Argentina's history and society with an approach that was generally known as scientific. In them a deeper exploration of archival records and the use of more solidly documented historical and sociological data played a central role. The current state of science in Argentina was not ignored by these authors. In 1900 a leading member of that generation, the historian Juan Agustín García, expressed concern that pure science, understood as experimental science, was still regarded as a luxury in Argentina and didn't have a single institution tending for it.

On the basis of these conceptions a more modern view of science and, in particular, an appreciation of experimental science, developed in Argentina. When a new and third national university was created in the new city of La Plata in 1905 its authorities, which moved in the same circles as García, declared their intention to make of it a temple for experimental science. They also expressed the wish to establish a closer link with the modern interests of the nation, particularly in the field of energy. In connection with physics it meant a contribution to the training of specialists in the new branches of the science of electricity. Experimental physics would clearly find a hospitable place there.

In an interesting new departure an Anglo-Saxon model was used for the structural design of this institution with colleges, student residences, sports facilities and a less formal relation between teachers and students. But above all there was a new appreciation of experimental science. The role of data collection and the notion of laboratory in the process of acquiring knowledge were understood in a very wide sense, as indicated before, which included more precise historical archive-research and extensive data-collection processes in social sciences studies. Pedagogy was also given a place as a science in this university, which trained secondary school teachers and had its own secondary school. The motto of this new institution was Pro Scientia et Patria.

An Institute of Physics was created in it and initially put in the hands of a local experimentalist, Teobaldo J. Ricaldoni, an engineer who had made his name as both a popular inventor dealing with submarines and other impressive machines and as an inspiring science teacher. Through his inventions he came into contact with electricity and radio telegraphy and, working closely with the navy, he became a pioneer of them in his country. He was also the author of a widely read physics textbook which, although no more than a free translation of Ganot's, as we have shown elsewhere, included fascinating accounts capable of firing the imagination of its young readers. The university provided Ricaldoni with ample funding to furnish his institute and adapt it for the teaching of modern physics with a particular emphasis on experimentation. His first task was to provide it with modern demonstration equipment. After consulting widely with foreign scientific instruments manufacturers he favoured offers from the German firm Kohl, in Chemnitz, over those of French instrument makers.

Figure 1 reproduces a caricature of Ricaldoni, published in a large circulation weekly magazine, which offers an interesting image of the public perception of a physicist in the in Argentina on 1901. Notice that Ricaldoni is cutting overhead wires, a reference to his work on wireless telegraphy, on the ground there is a fishbowl with a submarine in it, a reference to his best known invention, finally, also on the ground lays his popular Physics textbook.

By the end of the decade of 1900 the authorities of the University of La Plata began to consider the possibility of upgrading the scope of the Physics Institute, which had already 
attracted some gifted students, beyond basic teaching and to stimulate original enquiry in it, as in the humanity faculties.

In Argentina experimental scientists such as Walter Nernst were then perceived by some as leading academics, but also as men whose science was not confined to abstractions. They were closely connected with industrial production and capable of energizing it with the power of their science-based inventions. This was in line with the declared intentions of the creators of La Plata University for its role in Argentina.

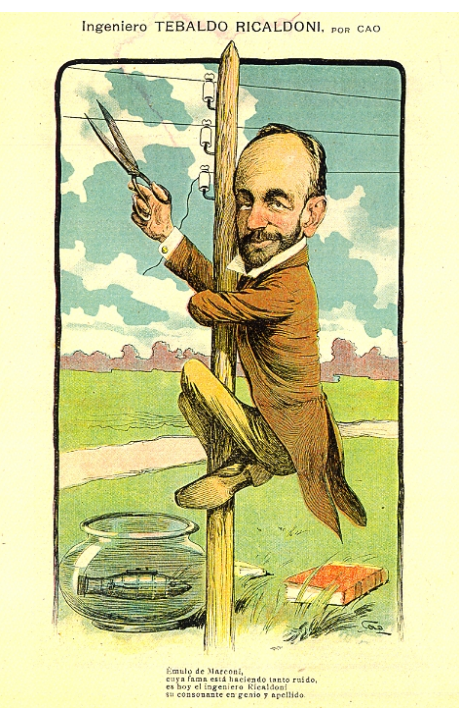

Figure 1

Teobaldo J. Ricaldoni

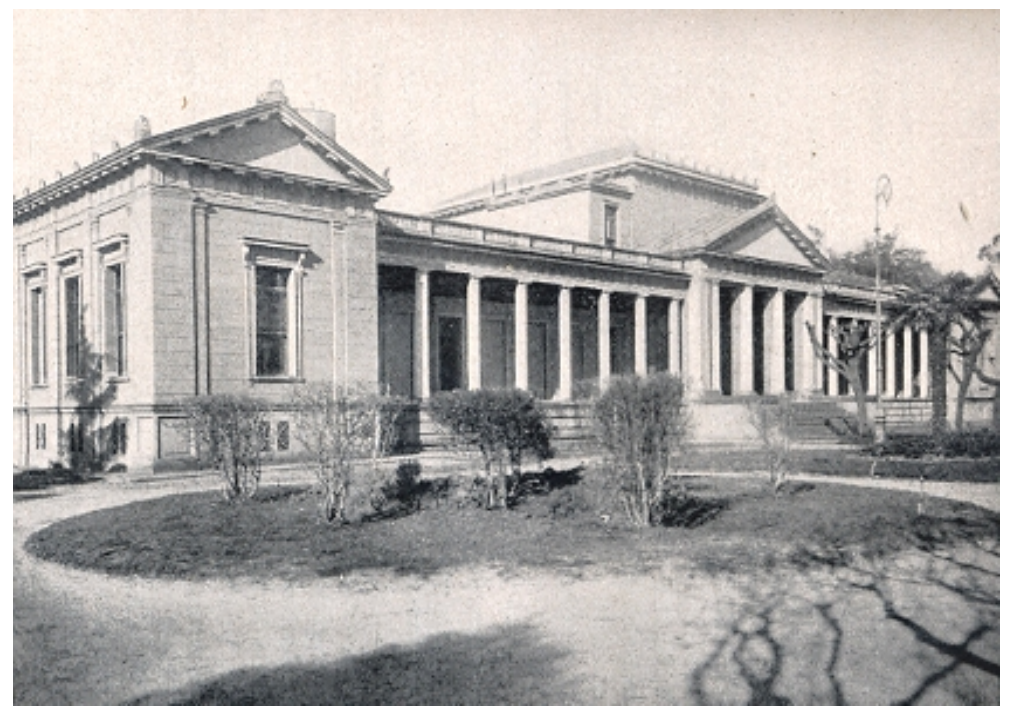

Figure 2

The La Plata Physics Institute

In 1909 Emil Bose, a former student of Nernst's, was invited to replace the local oldstyle inventor Ricaldoni as director of the Physics Institute. Later, other German, or Germantrained, physicists were appointed through Bose's intervention. Once in La Plata Bose, a skilled experimentalist who was also processing patents for his own inventions, worked hard to put the physics demonstration instruments acquired by Ricaldoni to really good use and to expand the institute infrastructure in a new building [3], which is shown in Figure $2 \mathrm{He}$ also made successful efforts to bring the students attracted in the earlier period closer to topics of modern experimental physics research. Sadly, Bose died less than a couple of years after his arrival, in mid 1911. As the University Vice-President said at his funeral, few foreign teachers had achieved so much in such a short period in Argentina's history.

The first Argentine professional physicists, Teófilo Isnardi, José Collo, and Ramón Loyarte, graduated by 1912 and were soon sent to Germany [4], [5], [6], [7]. They worked under Nernst or Plank and produced publishable scientific research. In the same years La Plata's astronomer and geodesy expert Félix Aguilar was also sent to Germany and France for further training in his field.

There was no reason for the German connection to be disrupted. After a short interim period, Bose was replaced by an even more outstanding research physicist, Richard Gans [8], who had made his name though valuable research work in the field of magnetism. Finally, in 1914 Nernst paid a personal visit to Argentina to lecture at La Plata. 


\section{The Positivist experiments: Córdoba and Buenos Aires}

If La Plata's was the most successful, it was not the only large experimental science effort in the early 20th century which could be associated with prevalent Positivist views in the contemporary cultural scene of Argentina. I shall refer briefly to two similar efforts, made in Córdoba and Buenos Aires, as they are also relevant to physics.

In 1909, around the time Bose moved to La Plata, the American astronomer Charles Dillon Perrine was designated director of the National Observatory, Córdoba, following a long line of American directors which started with Benjamin Gould nearly forty years earlier. Perrine was a practical astronomer with remarkable observational and technical skills, internationally known and already rewarded in Paris with the prestigious Lalande medal. In 1912 a German colleague, in close touch with Einstein, requested him to attempt to measure the light deflection predicted by the latter. His group in Argentina made the first attempt to measure that deflection in 1912 at an eclipse visible from Brazil, then in Russia in 1914 and finally in Venezuela in 1916. In all cases he and others failed because of bad weather. Sadly, he did not receive official funding to participate in the observation of the eclipse of 1919, when the weather was fine [9]. Another of his important initiatives was the expansion of the Observatory workshop, where he started working a large mirror that would have given Córdoba the second largest telescope in the world. Perrine faced considerable difficulties and work dragged on for many years.

A third, much neglected attempt to establish experimental sciences in Argentina, was conducted in Buenos Aires in 1900, that is, well before that of La Plata. Responsible for it was Miguel Cané, an outstanding Argentine writer who returned to Buenos Aires in the 1890s after many years working in Europe as a diplomatic representative of his country. From Europe, which he continued to visit after being Senator and Interior and Foreign Affairs Minister, he sent notes to Buenos Aires newspapers and in one of them, dated March 1896, he discussed an exhibition of X-rays in Paris in the year of their discovery. In France Cané had witnessed the cultural impact of Victor Duruy's École Practique des Hautes Études and in his periods in Central Europe he examined in detail the dynamics of some of Germany's leading universities. On his return Cané brought back a new and more sophisticated conception of culture and claimed that the "inquisitive minds" of young students should be helped to "move towards science". Specifically in relation to physics, Cané was deeply impressed by what he referred to as the "revocation of the principle of the immutability of matter" and to the impact of "the discovery of radio-active phenomena that revealed that what we call matter is nothing but energy".

Cané argued, with limited immediate success, that new infrastructure was required to update the culture of his country. He proposed that a modern centre for advanced studies in the sciences and humanities as well as an independent Faculty of Sciences, separated from that of Engineering, should be created. The first proposal was never accepted, while the second took place half a century later. In 1900 he was elected Dean of the Humanities Faculty (Facultad de Filosofía y Letras), which had been created only four years earlier. He saw the possibility of materializing his ideas there and attempted to give experimental sciences a platform in Buenos Aires at the new Humanities Faculty.

As the designers of the La Plata's experiment later, Cané believed that the notion of experience should be the foundation of science, be it physics, medicine or the social sciences, which he also wished to be ruled by quantitative measurement. By the time Cané left the Humanities Faculty, in 1904, it had already acquired a modern experimental psychology laboratory and, soon after, chairs and laboratories in experimental biology and a few other branches of science were added to it. The authorities made efforts to attract leading European experts to run these laboratories.

In a matter of a few years the Humanities Faculty created over twenty chairs covering a number on new fields in Argentina, such as ethnography, anthropology, sociology, history of art 
and education. The promoters of this project considered also introducing physics into their system. They were interested in the application of modern experimental physics techniques to the study of physical geography and invited Jacobo Juan Laub, a physicist previously associated with Einstein and brought to La Plata by Bose, to teach and conduct research on geophysics, particularly on terrestrial magnetism, aero-electricity and seismology. These were areas in which he had received training in Europe earlier. Laub remained associated with that Faculty for a short period until 1919. In these years he published general articles on relativity in Revista de Filosofia, a prestigious journal with Positivist leanings directed by José Ingenieros, who was a leading professor at both the Humanities and Medicine faculties.

Around 1910, quite independently, there was also some activity at the Engineering Faculty in Buenos Aires, but with a much more limited success. Lacking the commitment to experimental science and the laboratory facilities available in La Plata, modern physics in the Engineering Faculty at Buenos Aires could only focus on theory, for which it could draw on a longstanding background in mathematics, which goes back to the early efforts of Lanz and Mossotti and the more recent ones of Balbín and Duclout, particularly from the 1880s.

Camille Mayer, a French physics teacher who had been a classmate and friend of Henri Poincare in Nancy moved to Argentina in the 1890s and between 1909 and 1914 offered a series of lectures on mathematical physics. The first four were directly based on some of the advanced courses recently delivered by Poincaré in Paris, which had been published in book form. For the last of his courses he departed from Poincaré and followed the proceedings of the recent Solvay conference. In this course Meyer lectured on radiation and quantum theory; this is the first set of lectured on quantum theory delivered in Argentina. These lectures have been preserved: they were serialized in Anales de la Sociedad Cientifica Argentina and published as a book in 1915: Radiation and Quantum Theory [10]. Although he referred to Einstein's work on specific heaths, he did not discuss his work on relativity.

However, Meyer's free lectures were marginal to the life of the Engineering Faculty; they were never integrated into its official syllabus and remained optional. Still, their influence may not have been insignificant. We can find references to its positive impact in the recollections of some leading exact scientists trained in the early 1910s and in tributes to Meyer, who died in 1918. The unresponsiveness of the Engineering Faculty to give physics research a proper home in Buenos Aires in the decade of 1910 prompted a group of scientists, interested mainly in physical-chemistry, to revive the Mathematics and Mathematical Physics Seminar created in the 1890s by Balbín and Duclout at the Sociedad Científica Argentina, outside the Engineering Faculty. However, following Meyer's frustrated attempt there was change in the university system in Argentina towards the end of the 1910s, through the so-called University Reform, which had an effect on the position of sciences at the Engineering Faculty.

\section{The Positivist experiments come to a close: the renovation of mathematics and the onset of theoretical physics}

By the end of the 1910s the Positivist experiment Cané had started at the Humanities Faculty around 1900 was loosing momentum rapidly as the dominant philosophical outlook moved away from Positivism and its emphasis on experiment. Collection, taxonomy and measurement were now focussed through a more rigorous analysis. A group of young philosophers began to explore modern logic and the newly coined discipline of epistemology in the free atmosphere of the Humanities Faculty and opened a fierce critique of Positivism. They followed trends mapped by a variety of foreign influences, such as the works of philosophers $\mathrm{H}$. Bergson, E. Boutroux and E. Meyerson in France, B. Croce and G. Gentile in Italy, W. James in the USA and also by German neo-Kantian philosophers.

Coriolano Alberini, later in association with Alejandro Korn, was amongst the most dynamic personalities in that group of young critical philosophers whose influence culminated 
in the early 1920s when Alberini became Dean of the Humanities Faculty, in Buenos Aires. In 1923 he extended his influence to the old Positivist stronghold of La Plata, becoming professor of Gnoseology and Metaphysics there and giving a measure of how much Positivist influence had declined.

There was an important precedent: in 1916 the German-trained Spanish philosopher José Ortega y Gasset visited Argentina and offered a splendid set of lectures at the Humanities Faculty in which he discussed Kant and began to construct a technical critique of Positivism and of its methodological approach [11]. He perceived this as based on the uncertain concept of experience and relying excessively on external observation, with little reference to what he called "the exercise of internal senses". Ortega y Gasset also opened a discussion on the philosophical impact of the new physical theories. During his time in Germany he had been in contact with leading theoretical physicists, among others Hermann Weyl, whose wife Helene translated one of his most celebrated philosophical works into German. Surely by your standards, even by mine, Ortega y Gasset's physics was not always right. However, lecturing in a cultural milieu as Buenos Aires then was, where philosophy, literature and the arts had for a very long time been regarded as the zenith of culture, the very fact that he extracted the physical sciences from the mundane world of engineers' nuts and bolts and gave it a new deep cultural meaning, had a very considerable significance for its future.

In 1917-18 another Spaniard, Julio Rey Pastor, a brilliant 29 years-old mathematician trained in Göttingen and Berlin, was invited to Buenos Aires where he lectured on pure mathematics. He also lectured on the current crisis of mathematics, repeating a successful cycle given in Madrid in 1915. These lectures attracted physicists and mathematicians, but also philosophers; one of them, Korn has left his impression on the cultural resonance of this course. The impact of Rey Pastor's visit was unprecedented and at the request of his graduate students, at a time of intense change in the university, the authorities of a renovated Faculty of Engineering offered him a chair. He settled in Buenos Aires for good in 1922. His move had profound consequences for mathematics as well as for theoretical physics in Argentina. Figure 3, taken in Göttingen around 1915, shows Rey Pastor (second at the back) with his teacher David Hilbert (seated).

Rey Pastor was a function theorist with a vast mathematical and historical background. From the early 1920s he offered a series of advanced courses on topics such as tensor analysis, differential geometry, Riemannian geometry and partial differential equations, which helped some of his students read modern works on mathematical physics; the impact of his courses was amplified nationally by his diligence: as he had seen F. Klein doing in Göttingen, he wrote notes and his students published them.

\section{Einstein's visit to Argentina in $\mathbf{1 9 2 5}$}

Rey Pastor was critical of Positivism, as much as his friend Ortega y Gasset. Both admired Albert Einstein for what they perceived as an attempt to expand intellectual exploration and go beyond merely collecting more data. In their personal correspondence there are revealing critical references to what they refer to as the "data collection" activities of their Spanish physics colleagues.

In addition to the briefly mentioned astronomical attempts by Perrine, it is possible to detect some real interest in relativity in Argentina from around 1910. It was enhanced by a lecture given by Vito Volterra at the Sociedad Científica Argentina in 1910, when he was visiting in connection with the celebrations of the first centenary of Independence. Volterra directly referred to Einstein's work. Later, courses and contributions to local scientific or philosophical journals by Gans, Laub, and others supported the cause of relativity. As all over the world the results of Eddington's expedition had a considerable impact in Argentina sparking controversy and bringing the local discourse on that theory to a more precise and technical 
dimension. In 1922 the Sociedad Científica Argentina [12] organised a series of lectures on the new theory given by resident foreign scientists, such as Gans and Rey Pastor, as well as by the Argentine young physicists Collo and Isnardi and astronomer Aguilar. Their detailed and serious accounts were collected into a booklet in 1923.

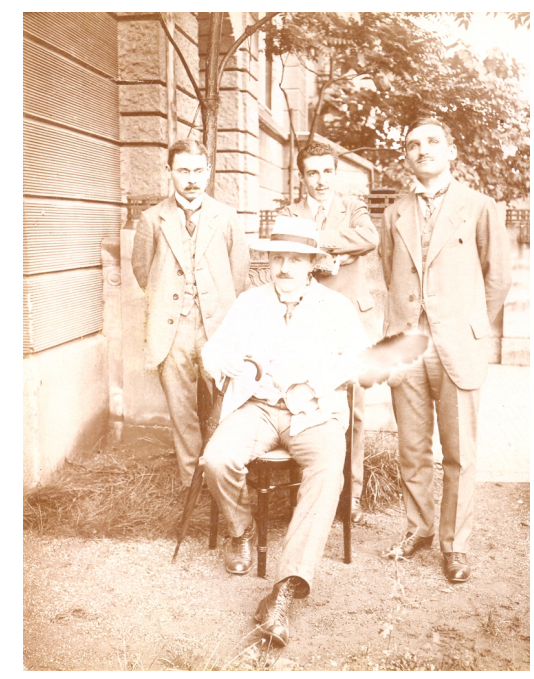

Figure 3

\section{J. Rey Pastor and D. Hilbert, Göttingen, 1915}

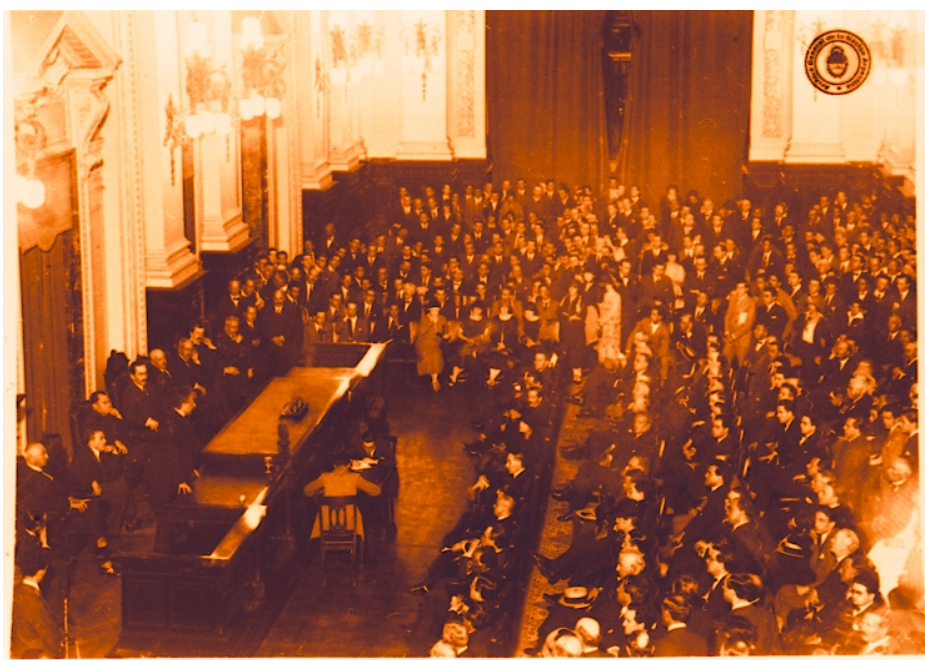

Figure 4

Einstein's course on Relativity Theory: the inaugural lecture, Buenos Aires, 1925

Partly through the offices of Rey Pastor, who visited him in Berlin in 1920, Einstein was invited to visit Spain, which he did in 1923 [13]. In 1922, before Einstein received the Nobel Prize for physics and at the same time as the Sociedad Científica Argentina's series mentioned above was in progress, the veteran Duclout proposed that the University of Buenos Aires should invite him to visit Argentina for one month and lecture on his theory of relativity, which he did in 1925.

Einstein's visit to Argentina offered a unique opportunity to reveal to the general public the real dimension of theoretical physics in the framework of modern science. Figure 4 shows the audience attending Einstein's first lecture, which forced the University to use its largest auditorium, at the University High School. Notice, in the right corner of the first row, the presence of female students attending this lecture. In the podium, on the sides of Einstein, seat several Secretaries of State and, just under it, on a small table, two physicists take notes of the lectures.

Figure 5 is a shot at the audience during one of the subsequent lectures. In the first row of this last picture we see some of the leading intellectuals and scientists of the time (such as mathematician C. C. Dassen, poet L. Lugones, engineer E. Butty, and physicists Isnardi and Loyarte) while the upper rows are occupied by younger academics and graduate students from Buenos Aires, La Plata and Montevideo who show attentiveness. Theoretical physics had never attracted such wide attention in Argentina before.

That visit has been discussed in some detail elsewhere [14]. I wish to concentrate here on a particular aspect of its cultural dimension: its connection with the Positivist and antiPositivist disputes, a topic that deserves some attention in relation to science. I wish to argue that Einstein's visit is associated with deep changes in the perception of science and research in Argentina, with a move towards theoretical studies and, also, of shifts in the emphasis of official patronage, which in the past cantered almost exclusively on experimental science. 
Duclout's initial proposal of 1922 quickly gained the support of academics from the Humanities Faculty; on the one hand Positivist scientists close to Ingenieros' and his Revista de Filosofia (which later serialized part of Einstein's lectures in Buenos Aires), on the other hand the anti-Positivist lobby close to Alberini. The latter was keen on a possible critique of Positivism by Einstein. Very recent research and the reconstruction of a manuscript of Einstein have shown that he actually intended to give a philosophically-oriented opening lecture to his relativity course [15]. However, he disappointed his anti-Positivist admirers by dropping the text he had prepared in favour of one which avoided facing the controversies between the two camps. Alberini invited him to the Humanities Faculty to open the academic year of 1925 but, again, Einstein did not condemned Positivism as expected from the text of Alberini's presentation.

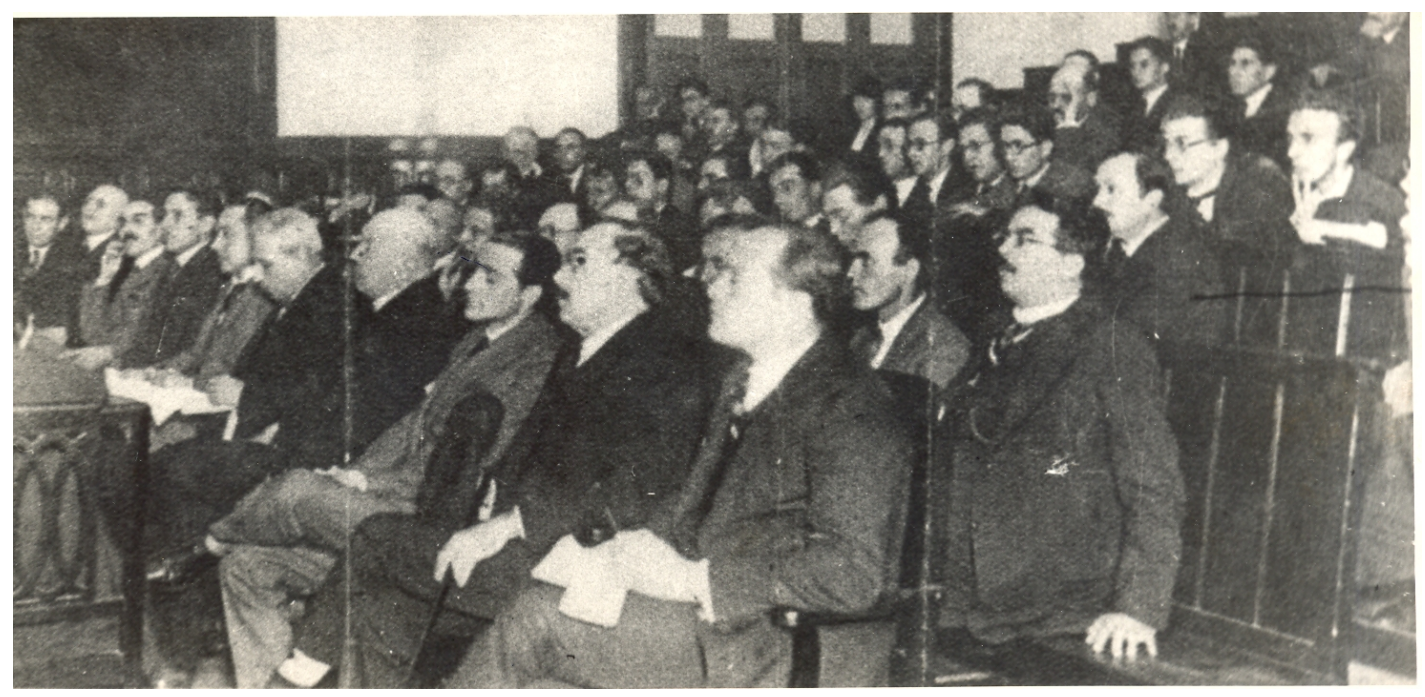

Figure 5

The audience of one of Einstein's lectures on Relativity Theory, Buenos Aires, 1925

Rey Pastor's teachings in Buenos Aires, and also in La Plata, where his influence extended, enabled at least a few members of Einstein's audience to follow the mathematical arguments given in the lectures. The minutes of Einstein's reception by the Buenos Aires Academy of Sciences show that Enrique Loedel Palumbo, one of Gans' graduate students from La Plata, asked him if "it is possible to represent bidimensional space-time surfaces in a Euclidean space of three dimensions" which, he said, had lead him to formulate a system of partial differential equations. According to the same minutes, Einstein replied, referring to these equations that "they have not been solved and the question of investigating the shape of a space-time surface would be very interesting". In fact differential geometer Edward Kasner, of Columbia University, had advanced a solution [16] to that problem four years earlier, embedding the solution in a flattened six dimensional space [17]. Loedel Palumbo' paper, which added a pictorial representation, was published by Physikalische Zeitschrift in 1926 [18]. In some ways, this short note opened a new chapter for physics in Argentina. However, after Einstein left, only a few continue discussing relativity and the subject slowly died. Loedel Palumbo soon moved to consider the philosophical foundations of relativity and other physical theories, particularly after a spell in Europe working under Erwin Schrödinger. 


\section{Physics in Argentina after Einstein}

We have made brief references to changes in the philosophical scene of Argentina and their impact on the Humanities Faculty, Buenos Aires, just before Einstein was invited to visit Argentina. Let us now examine briefly the situation of experimental physics in La Plata in that period, where, as we have indicated, the position of Positivism and the fervour for experimental science was also changing.

If contrasted against its early meteoric progress, physics in La Plata was showing some signs of fatigue. After a decade in La Plata, where he produced high-quality research work, in 1925 Gans was offered a chair in Germany and he decided to return. No doubt his country was scientifically far more exciting, but it was still seriously affected by the after impact of the war. Ironically, as he left emigration in the opposite direction was reaching a peak. The Argentine students of Bose's time, later sent to Germany, took over and began a process of "nationalisation" of physics teaching and, to some extent, also of research. Clearly, their vision, experience and contacts were not those of Gans. Loyarte took over as Director of the Physics Institute while Isnardi and Collo remained associated with the Institute, some times with differences of opinion. Isnardi taught physical-chemistry as well as mathematical physics, initially as Loyarte's assistant. Isnardi's first set of lectures covered three main areas: thermodynamics and radiation, electrodynamics and the special theory of relativity. The first part was based on works of Plank, the second on those of Becker, Poincaré and Abraham, and relativity on the works of von Laue, Eddington and the collection of papers of Lorentz, Einstein and Minkowski. Special topics were reserved for the second course. After Loyarte's death in 1944 Isnardi became full professor of mathematical physics until 1949.

A young and promising student at La Plata, Enrique Gaviola, who would later become the most remarkable Argentine experimental physicist of the first half of the twentieth century, was in the middle of his university studies when Gans left. He has said that Gans advised him to move to Berlin and continue his studies there, where he finally gained a doctorate under Peter Pringsheim, a former student of Nernst. Gaviola was not the only Argentine student moving to Germany in those years. They took advantage of the strong position of the Argentine currency in relation to the German Mark. Gans' advice, however, seems to define clearly enough his views on the prospects La Plata offered to a gifted student.

To summarise this period in La Plata it could be said that Bose's tenure showed that importing a well-trained physicist was definitely a positive step. It also showed the tensions a poor secondary-school physics training imposed on plans for the modernisation of university studies from the top. This is clearly reflected in Bose's interesting correspondence with Ricaldoni, who after leaving the direction of the Institute remained in charge of teaching basic physics courses. It turned out that raising the standards at the basic level, to allow for more advanced courses at the top of the career ladder, was much harder than expected. Despite these and other difficulties, as well as working hard in the installation the Institute's laboratory, Bose had also been very productive on the research side. In his less than two years in Argentina: three local physicists (Collo, Isnardi and Loyarte, who had started their studies in Ricaldoni's period) as well a German teacher working in Argentina began working for their doctorates under him and finished them shortly after his death, in 1912. Gans's decade, ending in 1925, added only three more doctoral dissertations in physics according to data given in [19].

Without leaving La Plata entirely, Isnardi and Collo became more closely associated with the Engineering Faculty at Buenos Aires. In addition, they taught physics at military and 
naval institutes and at secondary schools. Facilities for experimental research in Buenos Aires remained far below the standards of those at La Plata, which may have contributed to Isnardi and Collo's turning to theoretical topics in their physics interests.

The process of modernisation of physics and mathematics studies benefited from the creation of the Licenciatura and Doctorate in Physico-Mathematical Sciences at the Engineering Faculty in 1926, following a plan proposed by Duclout and Rey Pastor. This institutional landmark may be associated with the local impact of Einstein's visit. The new professional career benefited substantially from Collo and Isnardi's presence in Buenos Aires. The engineer Enrique Butty, a specialist in elasticity theory and a disciple of Duclout's, studied tensor calculus seriously in connection with his own field of work and was in a position to understand the mathematics of the general theory of relativity. Before Einstein's visit he contributed to make aspects of the theory accessible to the general as well as the specialist public, thereafter he took over the two university courses on Mathematical Physics for the Licenciatura. In his lectures he developed topics of differential geometry as well as tensor algebra and calculus, which he used to discuss relativity theory. His lessons were published by the university in two thick volumes [20], showing a new concern for the advance of Mathematical Physics.

Modernisation efforts received a further stimulus when Butty was elected Dean of the Engineering Faculty while Gaviola, back in Argentina and dissatisfied with the situation at La Plata, moved to Buenos Aires in 1930 and replaced Butty as Professor of Mathematical Physics. Although he left four years later, in his time there he shifted the contents of this course closer to theoretical, rather than mathematical physics, as Butty's course was. Isnardi replaced him and continued teaching it until 1952.

Changing views on instruments and experiment may have also had an impact on performance at the Córdoba Observatory, where the lavish support Perrine enjoyed in the initial years turned to be more moderate as the decade of 1910 came to an end. We already pointed to the fact that after going in an astronomical expedition to Russia in 1914 and to Venezuela in 1916 he failed to get support for an expedition to neighbouring Brazil to observe the eclipse of 1919. It has been already pointed out that technical difficulties to work the large mirror were found to be nontrivial. However, taking into account that Perrine was a skilled experimentalist, it is possible to conjecture that the project may not have been just an overoptimistic miscalculation, but that changing policies regarding financial support for large and expensive experimental science enterprises such as his may have also played a part.

\section{Some changes in the perception of science in the 1930s and its impact on physics}

Through the late 1920s and early 1930s some deep changes began to take place in the scene of science in Argentina. The number of scientists was increasing and they slowly began to be more autonomous in their views of their disciplines; less dependent on general trends from other fields of culture than in the past. They even began to contribute with their own views.

A new perception of scientific research became gradually clear to some Argentine physicists and mathematicians as well to other scientists, such as those in physiologist Bernardo A. Houssay's school. They believed that research should be regarded as a serious professional activity, a full-time occupation, as it was beginning to be accepted in some leading European countries.

There was also a more clear understanding that, in the past, some of the most gifted scientists (such as Collo, Isnardi and others in the case of physics) had been given the task of promoting research in Argentina but very limited means to carry it out. As it has already been mentioned, they earned their living teaching at a variety of institutions: universities, military and naval institutions and also secondary schools. Through the 1930s, this new perception of research as a profession generated a strong movement in which exact scientists Rey Pastor, Gaviola, Isnardi and others played a significant role. As part of a series of new institutional 
developments, outside the university system, an Argentine association for the advancement of science was created in 1933 [21]. However, their demands to academic and national authorities to professionalise scientific research took several decades to be accepted

\section{The onset of modern theoretical physics in Argentina}

In parallel, particularly after the military coup of 1930, the development of science at the universities became, gradually, a more distant objective for national authorities. Some new large scientific schemes, in cases connected with international projects, and not necessarily cantered at the universities, began to receive national support in decade of 1930. Aguilar, now director of La Plata's Observatory, conducted a successful geodesy project, part of an international effort, measuring a long Arc of Meridian along the territory of Argentina. His campaign demanded the coordination of complex and different tasks often on difficult terrain, long numerical computations and also to resolve some problems connected with physics research. In addition, the assistance given by the army and navy to Aguilar's campaign was a preliminary exercise of future army and science undertakings in the 1950s [1], [22].

In the late 1930s Gaviola left academia and joined the Córdoba Observatory, of which he later became director; he made efforts to facilitate a move into modern astrophysics there. In addition he took the significant step of sending Perrine's large mirror to be worked in the USA, implicitly recognizing the technical difficulty of the job. Gaviola and Aguilar deepened the contacts and cooperation between the two main observatories, Córdoba and La Plata.

Meanwhile, Rey Pastor's school was beginning to produce highly motivated students. Unlike their teacher, some of them expressed an interest in mathematical physics; Alberto González Domínguez was one of them. Although Rey Pastor had a direct intellectual influence in La Plata, it was through the initiative of two young academics there that the possibilities of discussing modern theoretical physics began to emerge, also in La Plata, in the mid 1930s. They were Agustín Durañona y Vedia, a young mathematician trained in Germany, and Alberto Sagastume Berra, a mathematician who had already collaborated with physicist Rafael Grinfeld in writing an introduction to quantum mechanics. In the mid 1930s these two teachers began to read M. Stone's 1932 book on linear transformations in Hilbert spaces with a group of graduate students. The experience they gained at this seminar made possible for them to explore the mathematical foundations of quantum theory in, for example, the works of J. von Neumann. Sagastume Berra also introduced his students to van der Waerden's Moderne Algebra, another mathematical work relevant to modern theoretical physics.

From the early 1940s the Second World War reduced the possibilities of communication with Europe, leaving open only a narrow corridor in the direction of the USA. In 1940 contacts with the US were considerably strengthened through a visit by Georges D. Birkhoff, the most senior mathematician at Harvard University, to Argentina [23], [24]. He stayed for over a month lecturing on function theory, the mathematical foundations of quantum mechanics and on his own version of the theory of relativity, an alternative to Einstein's. During his stay he paid personal attention to young promising scientists.

Birkhoff's visit marks an interesting turning point in the development of mathematics and mathematical physics in Argentina. It enhanced contacts with Harvard considerably. From a decade earlier they had been developing in the field of physiology through the efforts of Houssay in Buenos Aires and Walter Cannon at Harvard. Birkhoff had an important advantage over previous European visitors in that he enjoyed the support of large American institutions, particularly of the Guggenheim and Rockefeller Foundations, to facilitate the movement of scholars in the direction of the USA. For several years after that visit Argentine graduate students started to move almost exclusively to the USA. One of them was Eduardo Zarantonello, a student of Sagastume Berra at La Plata, who moved to Harvard and worked with Birkhoff's son Garrett. Together they wrote a classical book on advanced topics of theoretical 
hydrodynamics. Felix Cernuschi, a student from Buenos Aires who had gained a doctorate at Cambridge in 1938, working in statistical mechanics, joined his mentor and friend Gaviola at the Córdoba Observatory and in 1943 moved to Harvard to work with Birkhoff on ergodic theory.

In 1943 Gaviola secured theoretical physicist Guido Beck, who had been exiled in Portugal [25], a position at his Observatory. As he had done in so some many other places before, Beck drew young physicists to his place. One of them was José Balseiro, who had recently obtained a doctorate at La Plata [26]. Damián Canals Frau and Mario Bunge were also students of Beck's; their doctorates were awarded by La Plata in 1950 and 1952 respectively. In the same period Fidel Alsina Fuertes and Carlos Bollini finished their dissertations, also in La Plata, with work on classical electrodynamics and special relativity, and on the mathematical structure of quantum mechanics respectively.

In Buenos Aires Cecilia Mossin Kotin, the first female Argentine theoretical physicist, also worked under Beck's supervision while Juan José Giambiagi submitted a heavily mathematical doctoral dissertation supervised by González Domínguez in 1950. Other physicists, often moving from other fields of science or from newer universities, emerged also in this period.

This was the situation of mathematics, mathematical physics and theoretical physics and at the time Rubinstein, Daniel Bes and I joined Buenos Aires University, in 1950.

\section{Final remarks: Atomic energy, military coups, brain drain and its impact on physics in Argentina}

As a result of new concerns about the uses of atomic energy and an embarrassment which showed the vulnerability of the national government in highly technical areas [27], [28], a National Commission of Atomic Energy (CNEA) was created in Buenos Aires in the early 1950s. Although there had been a discussion in Parliament on the foundation of a physics and chemistry science research institute under civilian control, the CNEA was created under the direct tutelage of the armed forces [1]. However, it opened a more relaxed space for research than the universities, where political discriminations had been endemic, particularly after a military coup in 1943 that was followed by substantial dismissals in 1946. On of those dismissed in 1946 was Houssay. In 1947, still segregated from the university, he was awarded the Nobel Prize for Physiology and Medicine. In 1952 Collo, Isnardi, and Rey Pastor were also dismissed from Buenos Aires University. Isnardi was replaced by Balseiro, who made serious efforts to renovate teaching and introduce modern topics to facilitate a transition into modern nuclear physics. Again under the auspices of the CNEA, a physics institute with student's training facilities was created in Bariloche [29], using existing installations. Balseiro was designated its director and as a result of it he left Buenos Aires. After Balseiro's untimely death that institute was given his name.

In 1956 changes in the national political scene facilitated the migration of scientists from the CNEA back to the universities and the return of some who had gone abroad, Giambiagi as well as others. However, limited support to advanced training for over many years had left Argentina with only a few, albeit generous and enthusiastic, qualified specialists in advanced mathematics, theoretical physics and other fields. Mathematics, with a much stronger tradition and less dependence on instrumentation, was able to perform better than other disciplines.

Physicists D. Amati, J. C. Mallmann, H. Roederer, A. Sirlin were among the young graduates of this period. Theoretical physicist Bes has pointed out in a recent interview [30], that a new figure appeared among physics graduates in the late 1950s: the self-taught, a graduate student who looked for advice from abroad and, as soon as he could, moved overseas to complete his training. Hector Rubinstein was one of them: he moved to Columbia University. 
Through the early 1960s local efforts as well as the return of young graduates trained abroad contributed to enhance the position of the exact sciences in Argentina, while efforts were also done to facilitate the transition from the scientific training offered by secondary schools to the more advanced the universities were now demanding [31]. Form 1940 to 1966 the population of physics graduates increased sharply in Argentina, rising from some 15 to $60-70$ [32], [33].

From the institutional side again, the creation by UNESCO of an International Centre for Theoretical Physics in Trieste, in 1964, widened the possibilities for the training of theoretical physicists and benefited students in Argentina.

Sadly, the potential that then existed for further advances in physics and other sciences was affected by a new military coup in 1966. Following it, and repeating past mistakes, a large number of professors and assistants, many of them trained abroad, became separated from the universities. The activities of the Physics Department of Buenos Aires University's Faculty of Science "were practically reduced to zero for several months" as a result of loosing about $85 \%$ of the staff, including 17 out of its 19 professors according to [19, pp. 58, 135-6]. As in other difficult periods of Argentina's history, despite serious difficulties and fascinated by the subject rather than by the institutions, gifted young graduates continued to emerge. From 1983, after a return to democracy, efforts have been made to recover lost opportunities. However, instabilities generated during the military period contributed to sharpen the impact of the brain drain, which still demands considerable attention in Argentina.

\section{Acknowledgements}

I wish to thank the organizers of this meeting to honour the memory of Héctor Rubinstein, particularly Daniel Amati, Lars Bergstrom, and Elisabet Oppenheimer, for giving me an opportunity to discuss here some aspects of the history of science in Argentina in the first half of the $20^{\text {th }}$ century.

\section{References}

[1] E. L. Ortiz, Science and army in Argentina, in P. Forman and J. M. Sánchez Ron (eds.), National Military Establishments and the Advancement of Science and Technology. Kluwer Academic Publishers, Boston, 1996.

[2] E. L. Ortiz, and H. Rubinstein, La Física en la Argentina en los dos primeros tercios del siglo veinte: algunos condicionantes exteriores a su desarrollo, Rev. Brasil. Hist. Ciencia 02,1: 40-81, 2009.

[3] M. Bose, Das Physikalische Institut der Universität La Plata, Phys. Zeist., 12: 1230-1243, 1911.

[4] R. G. Loyarte, Evolución de las Ciencias en la República Argentina, II, Física, SCA, Buenos Aires, 1924.

[5] C. Galles, Sobre las primeras investigaciones en fisica realizadas en la Argentina, Ser. Fís. Part. y Campos, 6, 1982.

[6] L. Pyenson, Cultural Imperialism and the Exact Sciences. Peter Lang, New York, 1985.

[7] A. G. Bibiloni, Centenario de la Universidad Nacional de La Plata.

LaPlata.www.fisica.unlp.edu.ar/centenario/Centenario.

[8] E. Swinne, Richard Gans, Hochschullehrer in Deutschland und Argentinien, Berlin, 1992. 
[9] A. Gangui and E. L. Ortiz, First echoes of relativity in Argentine astronomy, in G. Romero, S. Cora, S. Cellone (eds), Historia de la Astronomia Argentina, Asoc. Argent. Astronomía, La Plata, 2009.

[10] C. Meyer, La radiación y la teoría de los quanta. Anales SCA, 8: 5-103, 153-245, 281-371, 1915.

[11] El curso de Don José Ortega y Gasset, Anales Inst. Cultural. Española de Buenos Aires, I: 140-208, 1947.

[12] A. Gangui and E. L. Ortiz, Enfoques cientificos de la relatividad en la Argentina, de 1910 a 1925 , 2011 (in the process of publication).

[13] T. F. Glick, Einstein in Spain, Princeton University Press, Princeton, 1988.

[14] E. L. Ortiz, A convergence of interests: Einstein's visit to Argentina in 1925, Ibero-Americanisches Arch., 20: 67-126, 1995.

[15] A. Gangui and E. L. Ortiz, Einstein's unpublished opening lecture for his course on Relativity Theory in Argentina, Science in Context, 21,3:435-59, 2008.

[16] E. Kasner, Finite representation of the Solar gravitational field in flat space of 6 dimensions, Amer. J. Maths, 43:130-33, 1921.

[17] J. Einsenstaed, The early interpretation of Schwarzschild solution, in D. Howard, and J. Stachel (eds.), Einstein and the History of General Relativity, Birkhäuser, Basel, 1989.

[18] E. Loedel Palumbo, Die Form der Raum-Zeit Oberfläche eines Gravitationsfeldes, das von einer punkt-förmigen Masse herrfürt, Phys. Zeits. 27:645-48, 1926.

[19] J. F. Westerkamp, Evolución de las Ciencias en la República Argentina, 1923-1972. II, Física. SCA, Buenos Aires, 1975.

[20] E. Butty, Introducción a la física matemática. I-II, Universidad, Buenos Aires, 1931, 1934.

[21] D. Hurtado de Mendoza and A. Busala, Los ideales de universidad "cientifica" (1931-1959). Eudeba, Buenos Aires, 2002.

[22] E. L. Ortiz, La Comisión Argentina del Arco de Meridiano, Oceanografía y Geofísica en el Atlántico Sur, Saber y Tiempo 19:127-188, 2005.

[23] E. L. Ortiz, La política interamericana de Roosevelt: George D. Birkhoff y la inclusión de América Latina en las redes matemáticas internacionales. Saber y Tiempo, 15: 55-112; 16, 16: 21-70, 2003.

[24] E. L. Ortiz, El giro de la física en la Argentina desde Alemania hacia los Estados Unidos: Gaviola Einstein y las fundaciones estadounidenses. Saber y Tiempo, 18: 123-158, 2004.

[25] E. L. Ortiz, Transferencias de Matemática Pura y Física Teórica de Portugal a Argentina en 194358: Beck, Monterio y Ruy Gomes, in M. do C. Silva, (ed.), Centro de Est. Mat., Universidade, Porto, 2003.

[26] A. López Dávalos and N. Badino, J. A. Balseiro, crónica de una ilusión. FCE, Buenos Aires, 2000.

[27] M. Mariscotti (1985). El secreto atómico de Huemul. Sudamericana, Buenos Aires, 2000.

[28] J. Hymans, The Psychology of Nuclear Proliferation. CUP, Cambridge, 2006. 
[29] L. Falicov, Physics and Politics in Latin America - A Personal Experience, Bul. Atomic Scientists. 810, 41-45, 1970.

[30] J. Martín and D. Hurtado de Mendoza. Entrevista a Daniel Bes, Ciencia Hoy, 15, 88:60-65, 2005.

[31] E. Díaz de Guijarro, Espíritu crítico y formación cientifica. Eudeba, Buenos Aires, 2010.

[32] T. Isnardi, La industria y la actividad cientifica en nuestro país, Inst. Est. Industriales, 2: 1-34,1943.

[33] F. Alsina, Que hacer por la física en la Argentina. Fundación Bariloche, Bariloche, 1968. 